\title{
Inhalt des LIII. Bandes
}

Kanonistische Abteilung XXII.

Frölich, Karl, Kirche und stādtisches Verfassungsleben im Mittelalter .. . . . . . . . . . . . . 188

Köstler, Rudolf, Ringwechsel and Trauung. Eine kirchen. nd deutschrechtliche Untersuchung ......... 1

Lohmann, Hans-Eberhard, Die Collectio Wigorniensis (Collectio Londinensis Regia). Ein Beitrag zur Quellengeschichte des kanonischen Rechts im 12. Jahrhundert . . . .

Stutz, Ulrich, Zu den ersten Anfängen des evangelischen Eherechts . . . . . . . . . . . . . . . . 288

\section{Miszellen:}

Caspers, Hans-Friedrich, Was bedeutet im Zeitalter Gregors VII. die Bezeichnung ,coepiscopus"? . . . . . 336

Genzmer, Erich, Zum Ordo Invocato Christi nomine . . . 380

Kuttner, Stephan, Collectio Francofortana . . . . . . $\mathbf{3 7 0}$

Opet, Otto, Cum sacramento divortium facere . . . . . . 332

Vetulani, Adam, Utber die Distinktioneneinteilung und die Paleae im Dekret Gratians . . . . . . . . . . . . 346

\section{Iiteratur:}

Acta Conciliorum Oecumenicorum ed. Eduardus Schwartz Tom. I Vol. I 2, 4, 5, 6, 7, 8; Vol. III. Tom. II Vol. II, III Besprochen von Hans Lietzmann.

Ascherfeld, Willy, Die Entstehung des lutherischen Konsistoriums in Essen . . . . . . . . . . . . 459 Besprochen von Johannes Heckel.

Bastgen, Hubert, Erzbischof Graf Spiegel von Köln und der Hl. Stuhl . . . . . . . . . . . . . . . . . . 450 Besprochen von Hans Erich Feine.

Birch-Hirschfeld, Anneliese, Geschichte des Kollegiatotiftes in Guttstadt . . . . . . . . . . . . . 436 
Diegel, Albert, Der päpstliche Einfluß auf die Bischofswahlen . . . . . . . . . . . . . . . . . . . 439

Besprochen von Leo Santifaller.

Diestelkamp, Adolf, Die geistliche Gerichtsbarkeit in den zur Diözese Halberstadt gehörigen Teilen der Kurmark usw. Angezeigt von Ulrich Stutz.

Fournier, Paul, und Le Bras, Gabriel, Histoire des collections canoniques II .............. . Besprochen von Ulrich Stutz.

Frank, P. Hieronymus, Die Klosterbischöfe des Frankenreiches . . . . . . . . . . . . . . Besprochen von Hans Barion.

Frotscher, Gerhard, Die Anschauungen von Papst Johann XXII. über Kirche und Staat . . . . . . . . . . . . . 443 Besprochen von Richard Scholz.

Gerlach, Friedrich, Der Archidiakonat Lemgo . . . . . 409 Besprochen von Hermann Nottarp.

Gorino, Mario, La costituzione giuridica del capitolo cattedrale di Asti . . . . . . . . . . . . . . . . . . . . Besprochen von Ulrich Stutz.

Grau, Wilhelm, Das Kirchenpatronat in Württemberg unter der Verfassung vom 25. September 1919. . . . . . . . Besprochen von Arthur B. Schmidt.

Gresky, Wolfgang, Der thüringische Archidiakonat Jechaburg .. . . . . . . . . . . . . . . . Besprochen von Johannes Bauermann.

Große-Wietfeld, Franz, Justizreformen im Kirchenstaat in den ersten Jahren der Restauration . . . . . . . . Besprochen von Joh. Bapt. Sägmüller.

Haa B, Robert, Die Kreuzherren in den Rheinlanden ... Bsprochen von Siegfried Reicke.

Heinemann, Carl, Die Kollationsrechte des Stifts S. Kunibert zu Köln . . . . . . . . . . . . . . . . . . Besprochen von Franz Gescher.

Just, Leo, Zur kirchenpolitischen Lage in Osterreich beim Regierungsantritt Franz II. . . . . . . . . . . . . . 463 Angezeigt von Hans Erich Feine.

Lerner, Franz, Kardinal Hugo Candidus. Besprochen yon Ulrich Stutz.

Molitor, Abt Raphael, Aus der Rechtsgeschichte benediktinischer Verbände II . . . . . . . . . . . . . . . . . 444 Besprochen von Hermann Nottarp. 
Müller, Michael, Ethik und Recht in der Lebre von der Verantwortlichkeit . . . . . . . . . . . 455

Besprochen von Stephan Kuttner.

Nasalli Rocea di Corneliano, Emilio, La corte di Fombio

e il Comune di Piacenza nel sec. XIII . . . . . . . . 461

-, -, Il card. Bessarione legato pontificio in Bologna . . 461 Angezeigt von Ulrich Stutz.

Nottarp, Hermann, Zur Communicatio in sacris cum haereticis

Angezeigt von Hans Erich Feine.

Paas, Theodor, Die Pfarre St. Maria Lyskirchen zu Köln 416 Besprochen von Franz Gescher.

Ronneberger, Werner, Das Zisterzienser-Nonnenkloster zum

Heiligen Kreuz bei Saalburg a. d. Saale . . . . . . . 413 Besprochen von P. Paulus Volk.

Schuler, Matthias, Über die Anfänge des Christentums in

Gallien und Trier ............... 404 Besprochen von Wilhelm Levison.

Schwartz, Eduard, siehe Acta Conc. Oec. . . . . . . 389

Tatarin-Tarnheyden, Edgar, Die Enteignung des deutschen Doms zu Riga. . . . . . . . . . . . . . . 460 Besprochen von Hans Gerber.

Voß, Lena, Heinrich von Blois, Bischof ron Winchester (1129-71) . . . . . . . . . . . . . . 438 Besprochen von Martin Weinbaum.

Weiler, Peter, Die kirchliche Reform im Erzbistum Köln 1583-1615 . . . . . . . . . . . . . . . . . 423 Besprochen von Franz Gescher.

Weinzierl, Karl, Rückgabepflicht nach kanonischem Recht 453 Besprochen von August Hagen.

Verzeichnis der sonst eingegangenen Schriften . . . . . 463

\section{Kanonistische Chronik:}

Codicis iuris canonici fontes VI . . . . . . . . . . . . . . 464

August Naegle $\dagger$ von Johann Schlenz. . . . . . . . . 464

Ludwig Wahrmund †. - Wilhelm Kahl †. - Karl Rothen-

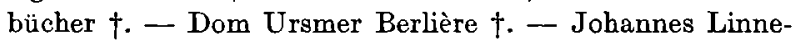
born $t$. . . . . . . . . . . . . . . 466

Personalnachrichten .. . . . . . . . . . . . 468

Kurzer Bericht über die dritte Tagung deutscher Rechtshistoriker zu Jena von Siegfried Reicke.......... 